\title{
Time-resolved pathogenic gene expression analysis of the plant pathogen Xanthomonas oryzae pv. oryzae
}

\author{
Seunghwan Kim', Yong-Joon Cho ${ }^{2}$, Eun-Sung Song ${ }^{1}$, Sang Hee Lee ${ }^{3}$, Jeong-Gu Kim ${ }^{1 *}$ and Lin-Woo Kang ${ }^{4^{*}}$
}

\begin{abstract}
Background: Plant-pathogen interactions at early stages of infection are important to the fate of interaction. Xanthomonas oryzae pv. oryzae (Xoo) causes bacterial blight, which is a devastating disease in rice. Although in vivo and in vitro systems have been developed to study rice-Xoo interactions, both systems have limitations. The resistance mechanisms in rice can be better studied by the in vivo approach, whereas the in vitro systems are suitable for pathogenicity studies on $X_{0 O}$. The current in vitro system uses minimal medium to activate the pathogenic signal (expression of pathogenicity-related genes) of $X_{0}$, but lacks rice-derived factors needed for Xoo activation. This fact emphasizes the need of developing a new in vitro system that allow for an easy control of both pathogenic activation and for the experiment itself.

Results: We employed an in vitro system that can activate pathogenicity-related genes in Xoo using rice leaf extract $(R L X)$ and combined the in vitro assay with RNA-Seq to analyze the time-resolved genome-wide gene expression of Xoo. RNA-Seq was performed with samples from seven different time points within $1 \mathrm{~h}$ post-RLX treatment and the expression of up- or downregulated genes in RNA-Seq was validated by qRT-PCR. Global analysis of gene expression and regulation revealed the most dramatic changes in functional categories of genes related to inorganic ion transport and metabolism, and cell motility. Expression of many pathogenicityrelated genes was induced within 15 min upon contact with RLX. hrpG and hrpX expression reached the maximum level within 10 and 15 min, respectively. Chemotaxis and flagella biosynthesis-related genes and cyclic-di-GMP controlling genes were downregulated for $10 \mathrm{~min}$ and were then upregulated. Genes related to inorganic ion uptake were upregulated within $5 \mathrm{~min}$. We introduced a non-linear regression fit to generate continuous time-resolved gene expression levels and tested the essentiality of the transcriptionally upregulated genes by a pathogenicity assay of lesion length using single-gene knock-out Xoo strains.

Conclusions: The in vitro system combined with RNA-Seq generated a genome-wide time-resolved pathogenic gene expression profile within $1 \mathrm{~h}$ of initial rice-Xoo interactions, demonstrating the expression order and interaction dependency of pathogenic genes. This combined system can be used as a novel tool to study the initial interactions between rice and Xoo during bacterial blight progression.
\end{abstract}

Keywords: Pathogenicity, Plant-pathogen interactions, RNA-Seq, Time-resolved genome-wide gene expression, Xanthomonas oryzae pv. oryzae

\footnotetext{
*Correspondence: jkim5aug@korea.kr; Ikang@konkuk.ac.kr

${ }^{1}$ Genomics Division, National Academy of Agricultural Science (NAAS), Rural

Development Administration (RDA), Jeonju 54874, Korea

${ }^{4}$ Department of Biological Sciences, Konkuk University, 1 Hwayang dong,

Gwangjin-gu, Seoul 05029, Korea

Full list of author information is available at the end of the article
} 


\section{Background}

Plants and pathogens have competed with each other throughout evolutionary history. Initial plant-pathogen interactions are crucial in determining the fate of infection to cause disease or to elicit hypersensitive reactions in resistant plants. Plants resist infection by a two-tiered innate immune system of pathogen-associated molecular pattern-triggered immunity and effector-triggered immunity [1]. Pathogen-derived pathogen-associated molecular patterns and plant-derived damage-associated molecular patterns are recognized by plants and activate plant resistance. On the contrary, the pathogen tries to avoid plant resistance by activating its pathogenic system, represented by effector secretions.

Rice (Oryza sativa L.) has contributed significantly to global food security in the Green Revolution of the 1960s and still remains the most widely consumed staple food globally. As the world population rapidly grows, rice production needs to increase by at least $25 \%$ by 2030 under more severe environmental stresses like climate change and disease pressures [2]. Among rice diseases, bacterial blight is a destructive disease that results in severe losses, ranging from 10 to $20 \%$ and up to 50 to $70 \%$ in Asian countries [3, 4]. Bacterial blight is a vascular disease that causes tannish gray to white lesions along the leaf veins resulting in rapid drying of severely infected leaves [3]. The gram-negative plant pathogen Xanthomonas oryzae pv. oryzae (Xoo) is the causative agent of bacterial blight on rice [5]. Recently, qualitative and pathogen race-specific resistance to Xoo has been conferred in plants by introduction of major disease resistance genes [6]. In addition to Xoo on rice, pathogens of the genus Xanthomonas infect nearly 400 different plant hosts, including rice, cotton, soybean, oil-rape, citrus and banana, which are economically important crops [7].

In Xoo, many virulence genes have been identified, including those related to hypersensitive responses and pathogenicity ( $h r p)$, bacterial toxins and effectors of avirulence $(a v r)$, plant cell wall degradation, extracellular polysaccharide synthesis and secretion, and bacterial motility and chemotaxis $[8,9]$. For instance, the type 3 secretion system (T3SS) encoded by hrp genes enables Xoo to inject T3 effectors into the host rice cells [10]. The OmpR-type response regulator HrpG is known to control the expression of genome-wide pathogenicityrelated regulons, including hrp genes, T3 effectors and virulence genes, through another regulator known as HrpX [11]. Both tonB and bfr genes are essential for competing for iron uptake with the host [12, 13]. Chemotaxis and motility-related genes are also known to be controlled by hrp genes such as hrpG and $h r p X$ [14]. A second messenger such as cyclic-di-GMP affects a wide array of pathogenic cellular functions, including type III secretion and virulence [15-20]. The twocomponent regulatory systems of PhoB-PhoR and PhoP-PhoQ are also closely involved in pathogenicity signaling [21].

It is known that hrp genes are only induced when phytobacteria are grown in the plant leaf apoplast or in close contact with plant cells [22, 23]. In order to activate the pathogenicity of the phytobacteria Xanthomonas represented by hrp gene expression, synthetic minimal medium such as XOM2 and XVM2 was used, which is known to mimic the plant apoplast environment to activate the pathogenic signals [24-27]. Xoo can be cultured in artificial media but the minimal medium condition is required to activate $h r p$-related gene expression. It is difficult to activate pathogenic signals in Xoo at the desired time point using the synthetic minimal medium. Mutant Xoo strains are usually used to study the pathogenic role of target genes by the comparison with wild-type Xoo strains. In this study, we used an in vitro assay system that activates $X o o$ pathogenicity by treating Xoo cells with rice leaf extracts (RLX) [28, 29]. The in vitro assay system using RLX could induce the expression and secretion of putative effectors of XoAvrBs2 and Xo2276 (AvrBs3-type TAL effector-like protein) and the T3SS-dependent secretions of XoAvrBs2 and Xo2276 were confirmed at $4 \mathrm{~h}$ after RLX treatment. The in vitro assay system with RLX enables activation of the pathogenic signal in Xoo at any specific time. We analyzed time-resolved genome-wide gene expression of Xoo by combining the in vitro assay system with RNA-Seq, allowing us to compare pathogenic gene expression patterns in the same genetic background without using single-gene knockout mutants. The time-resolved transcriptome data of Xoo were verified by qRT-PCR.

\section{Results}

\section{In vitro assay system and RNA-Seq}

We combined an in vitro assay system with RNA-Seq to analyze genome-wide pathogenic gene expression of Xoo in a time-dependent manner (Fig. 1a). The in vitro assay system consists of fresh RLX preparation by grinding the leaves of a Xoo-susceptible rice cultivar (Milyang23) in liquid nitrogen and addition of RLX at the mid-exponential phase of Xoo cell culture in nutrient broth. Samples were harvested for RNA-Seq from the RLX-treated (Pathogenicity-activated; P-activated) and untreated (control) Xoo cells at specific time points. RNA-Seq data were verified by qRT-PCR in separate biological replicates.

The first hour after RLX treatment was examined by RNA-Seq using seven different time points of $0,5,10$, 15, 30, 45 and 60 min (Additional file 1: Table S1). Most of the pathogenicity-related genes were upregulated within the first $30 \mathrm{~min}$. To validate RNA-Seq data of the 


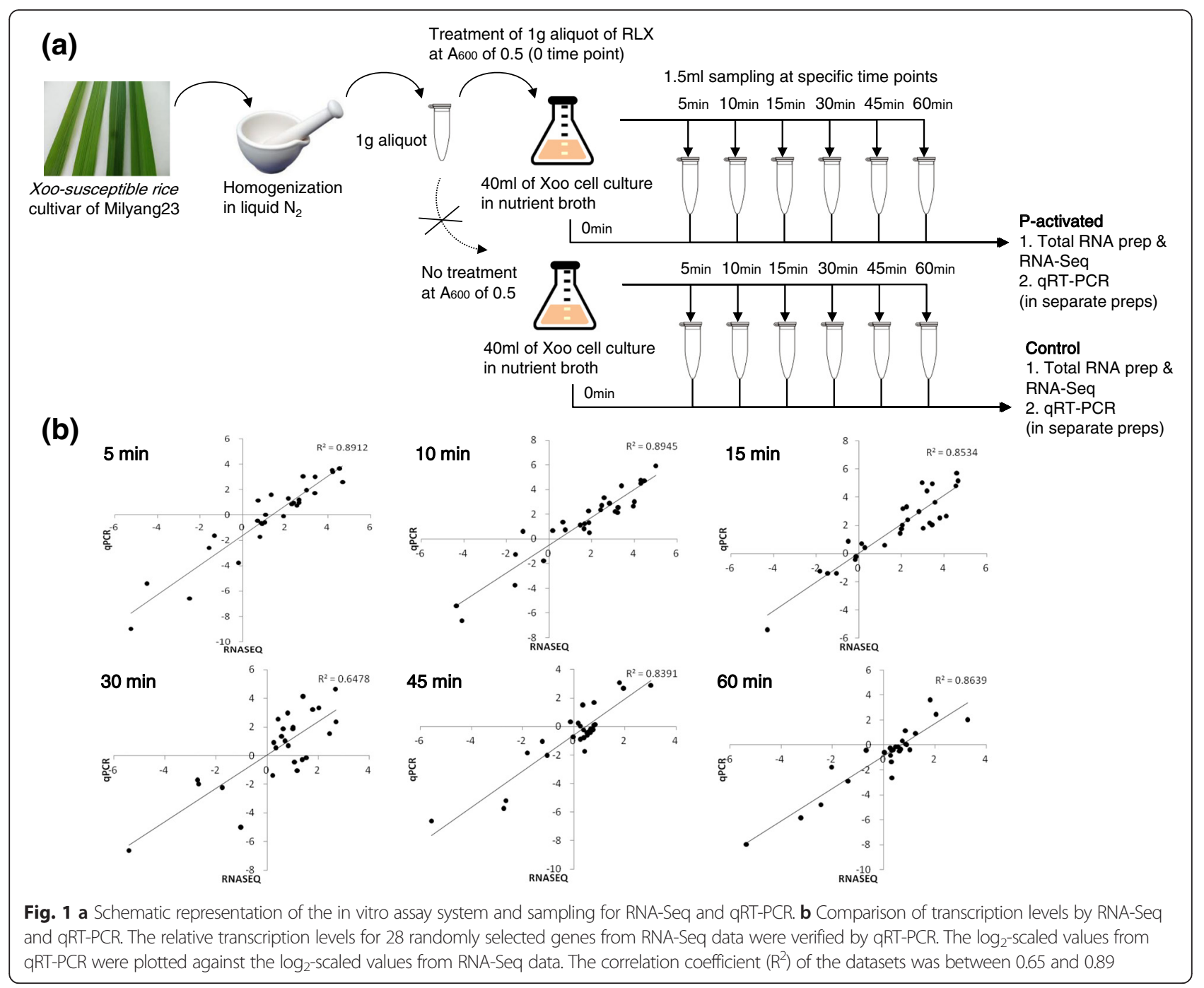

first hour, qRT-PCR was performed with 28 arbitrarily selected up- or downregulated Xoo genes from the RNA-Seq data (Additional file 2: Table S2). Significant correlation was observed between the $\log _{2}$-fold changes in the expression levels determined by RNA-Seq and qRT-PCR (Fig. 1b).

\section{Time-resolved gene expression patterns on Clusters of Orthologous Groups (COGs)}

RNA-Seq experiments were performed with total RNA extracts from both P-activated and control Xoo cells. The RNA-Seq data covered more than 4125 ORFs of Xoo, which constitutes $89 \%$ of all 4637 annotated protein-coding ORFs (Additional file 3: Table S3). For each gene, two different conditions (P-activated and control) and seven time-dependent expression levels of RNA were examined. For each gene in the whole genome, pathogenicity condition, gene expression level and time resulted in three-dimensional data. In control cells, the expression levels of most pathogenicity-related genes remained unchanged. In order to compare time-dependent transcriptional expression of all genes, we set the expression level at zero time point as the reference level of 1 for each gene. Accordingly, expression levels at all time-points were divided by that at the zero time point and uniformly started from 1 at the zero time point, which simplifies the comparison of time-dependent changes in gene expression levels.

RNA-Seq data showed that in P-activated Xoo cells, $305,325,300,291,204$ and 224 genes were upregulated, whereas 110, 173, 148, 179, 210 and 205 genes were downregulated at each of the 6 time points, respectively, with an RPKM threshold of 2.0 and a difference filter of 2.0 (Additional file 4: Figure S1). The number of upregulated genes reached the maximum of 325 genes at $10 \mathrm{~min}$ point and decreased to 204 genes at $45 \mathrm{~min}$ point. The number of downregulated genes slowly increased until $1 \mathrm{~h}$ in a time-dependent manner. 
In order to study the global gene expression pattern, we superimposed time-dependent gene expression patterns of genes according to functional categories in the clusters of orthologous groups (COG) database (Fig. 2 and Additional file 5: Table S4), with a further grouping into three classes (red, yellow and blue) depending on the observed pattern. The biggest changes in gene expression of Xoo cells upon RLX treatment were observed in the categories of inorganic ion transport and metabolism $(\mathrm{P})$ and cell motility $(\mathrm{N})$ further classified as red class (red boxes in Fig. 2). In category P, many genes were found to be upregulated from 5 min by more than 5 -fold. In category $\mathrm{N}$, many genes were downregulated until $15 \mathrm{~min}$ and were then upregulated from $30 \mathrm{~min}$. Class yellow grouped genes that showed initial moderate upregulation followed by return to the original level of gene expression. This class had genes belonging to other 9 categories (yellow boxes in Fig. 2) namely of signal transduction mechanisms $(\mathrm{T})$, transcription $(\mathrm{K})$, posttranslational modification, protein turnover, chaperones $(\mathrm{O})$, cell wall/membrane/envelope biogenesis $(\mathrm{M})$, energy production and conversion $(\mathrm{C})$, carbohydrate transport and metabolism (G), lipid transport metabolism (I), general function prediction only (R), and function unknown (S). In category $\mathrm{T}$, key pathogenicity regulator genes such as $h r p G$, hrpX and two-component system (TCS) genes including $p h o B-p h o R$ and $p h o P-p h o Q$ were upregulated from $5 \mathrm{~min}$ and returned to the original expression level at $1 \mathrm{~h}$ time point. In category $\mathrm{M}$, gum genes were upregulated from 5 to $10 \mathrm{~min}$ and in G, sugar-transporting genes like fruK, fruA and fruB were upregulated from $5 \mathrm{~min}$. Whereas the last grouping class, blue, contains genes belonging to other nine categories which expression levels showed little changes or stayed at almost the same level as the zero time level, with the exception of only a few genes.

\section{hrp genes}

The hrp genes are key global regulators of pathogenicity and play important roles in T3SS and virulence [10]. Our in vitro RNA-Seq data revealed that the expression of $h r p G$ was induced within $5 \mathrm{~min}$, and maximum expression was observed at $10 \mathrm{~min}$. $h r p X$ expression also started to increase within $5 \mathrm{~min}$ but at a slower rate and continued to increase until 15 min when maximum expression was achieved (Fig. 3a). The RNA-Seq result was confirmed by qRT-PCR. Most hrp genes were upregulated within $1 \mathrm{~h}$ (Additional file 6: Figure S2). In the other in vitro system using the hrp genes-inducing minimum medium, the expression of hrp genes was also

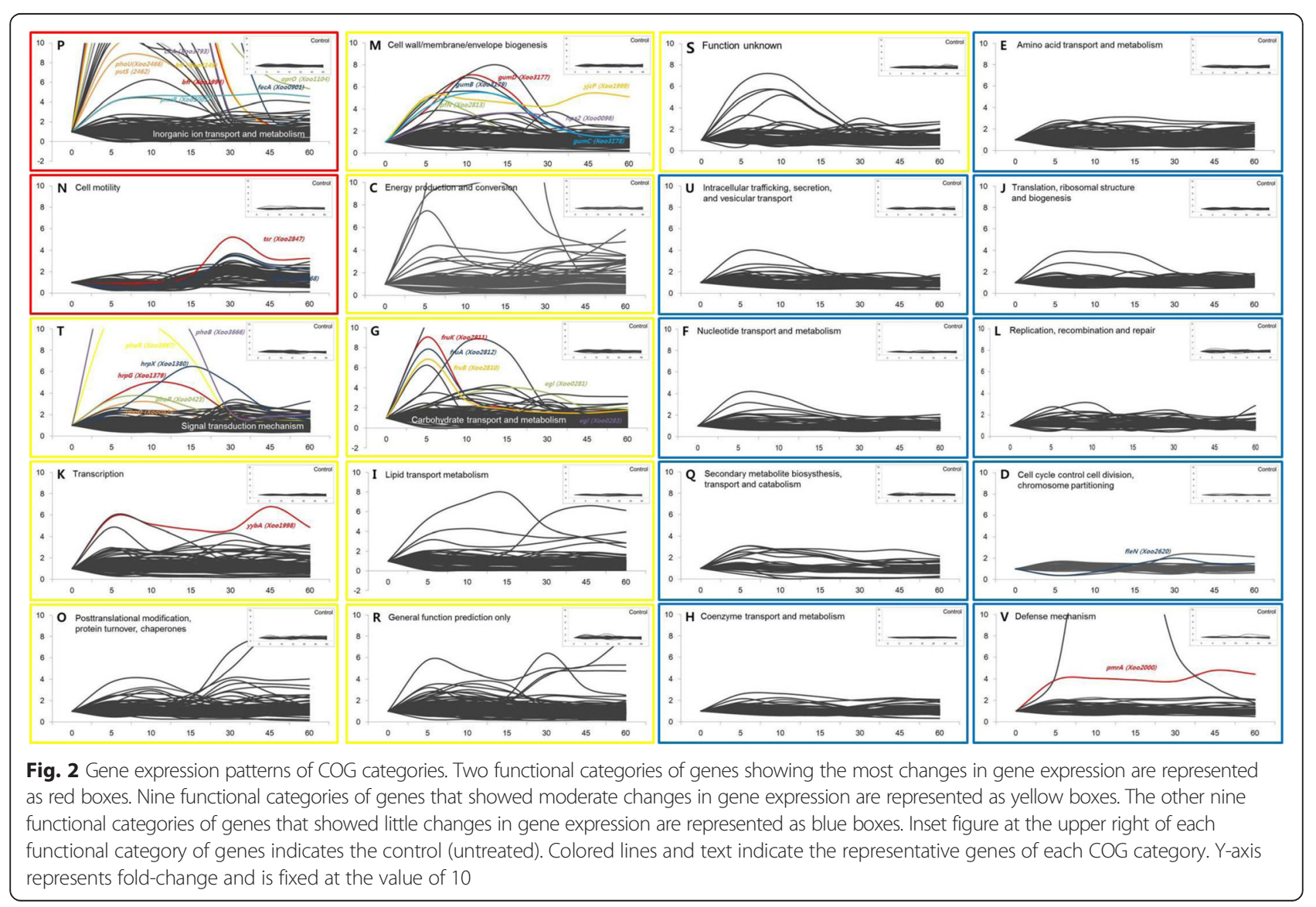



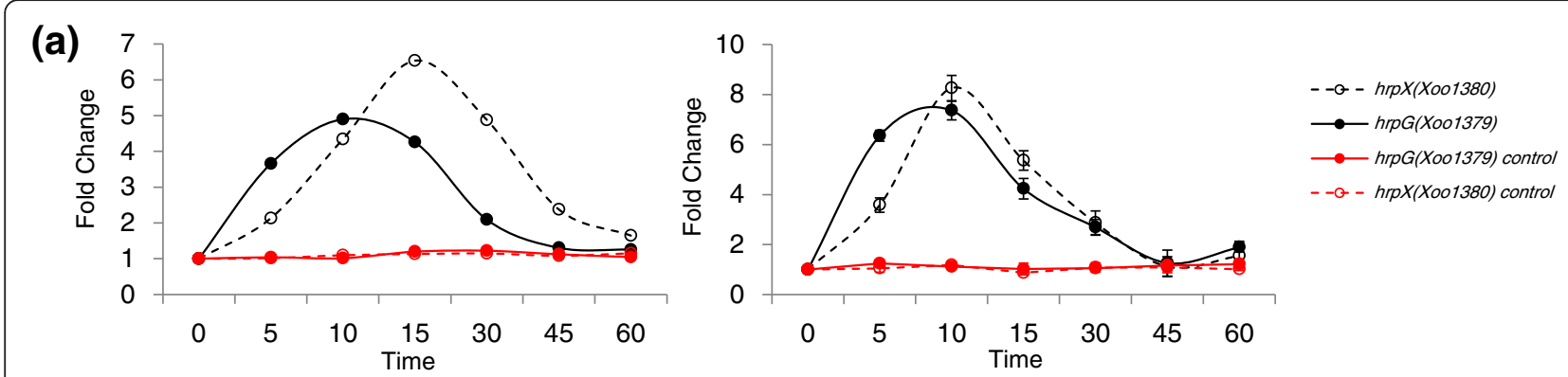

(b)
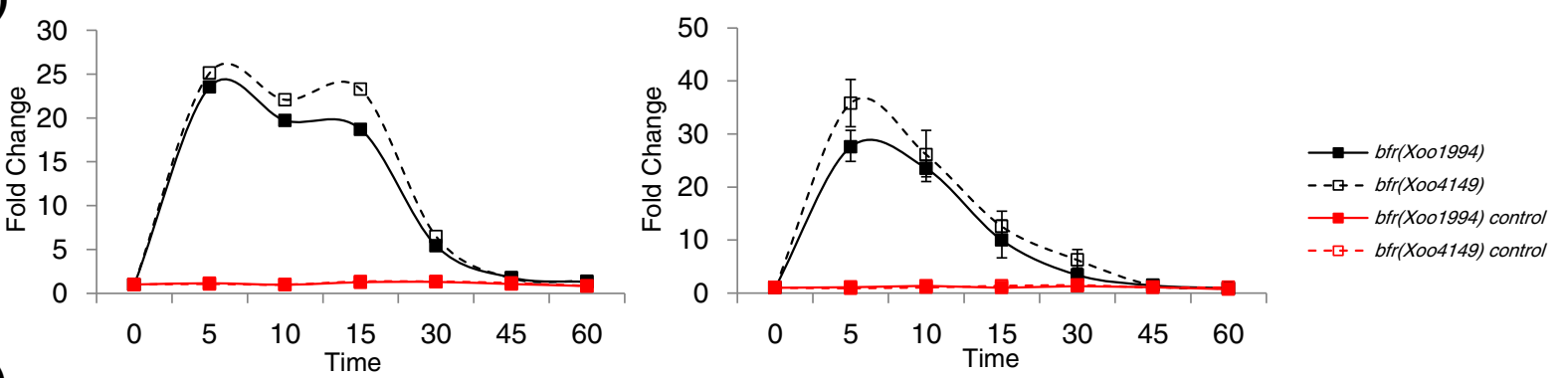

(c)
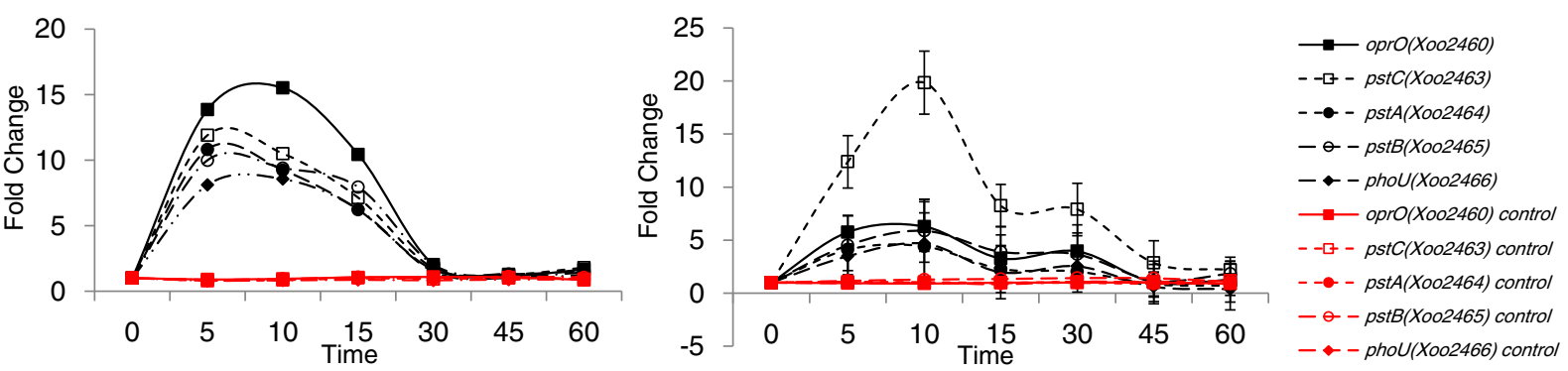

Fig. 3 Time-resolved expression patterns of $h r p G$ and $h r p X$ genes, iron-uptake bacterioferritin genes and Pi-uptake genes. a RNA-Seq expression data of $h r p G$ and $h r p X$ (left) and qRT-PCR expression data of hrpG and hrpX (right). b RNA-Seq expression data of two bacterioferritin genes, Xoo 1994 and Xo04149 (left) and qRT-PCR expression data of Xoo1994 and Xoo4149 (right). c RNA-Seq expression data of oprO, pstC, pstA, pstB and phoU (left) and qRT-PCR expression data of oprO, pstC, pstA, pstB and phoU (right). The unit of time is min. Red lines indicate the expression levels of genes in the control (untreated) Xoo cells. Y-axis represents fold-change

upregulated similarly but mostly at higher levels [30] (Additional file 7: Table S5).

\section{Inorganic ion transport and metabolism-related genes}

In 20 categories of COG, P showed the largest number of upregulated genes. Iron-uptake related genes and inorganic phosphate-uptake related genes are the representative upregulated genes in P. In most living organisms, iron is an essential nutrient required for many important biological processes [12]. Pathogenic bacteria need to compete with their host to obtain iron; for instance, by producing and secreting bacterioferritins and siderophores in the host, which are high-affinity Fe (III) scavengers [13]. The bacterioferritin (bfr) genes are involved in storing ferric iron after uptake [31]. The expression of bfr genes Xoo1994 and Xoo4149 were upregulated at $5 \mathrm{~min}$ (Fig. $3 \mathrm{~b}$ ).

Iron-loaded siderophores are transported back into bacterial cells through an outer membrane receptor, which is regulated by other membrane-associated proteins such as TonB [32, 33]. Our results showed that Xoo2114 (among the seven TonB proteins of $\mathrm{Xoo}$ ) was upregulated at $5 \mathrm{~min}$ (Additional file 8: Figure S3A). Among 24 TonBdependent receptors, fecA (Xoo0901) and $\operatorname{cirA}$ (Xoo3793) were upregulated from $5 \mathrm{~min}$; notably, fecA (Xoo0901) expression increased by more than 80 -fold at $10 \mathrm{~min}$ (Additional file 8: Figure S3B). On the contrary, iroN (Xoo0394), iroN (Xoo1784) and cirA (Xoo4431) were downregulated (Additional file 8: Figure S3C). fyuA (Xoo1099) was upregulated at $5 \mathrm{~min}$ and downregulated afterwards. Among the exb genes, also involved in ferric iron uptake [34], only tolR (Xoo1666) showed upregulation from 5 to $15 \mathrm{~min}$ (Additional file 8: Figure S3D). The iron-uptake genes, highly expressed before the 5 min time point, can be good candidates as early initiators to activate the pathogenicity signal in Xoo.

Inorganic phosphate $(\mathrm{P} i)$ is another essential nutrient depleted by the host as a protective mechanism against 
bacterial infection. However, this depletion is sensed by some pathogens and prompts the expression of virulence genes. The P $i$-specific transport operon, pstSCABphoU, was upregulated from $5 \mathrm{~min}$; pstC (Xoo2463 encoding the phosphate $\mathrm{ABC}$ transporter permease), pstA (Xoo2464 encoding the phosphate ABC transporter permease), pstB (Xoo2465 encoding the phosphate transporter ATP-binding protein), and phoU (Xoo2466 encoding the phosphate uptake regulator) were upregulated at 5 min by 12, 11, 10 and 8-fold, respectively (Fig. 3c). The pstSCAB-phoU genes are activated by the twocomponent system of PhoB-PhoR that detects and responds to changes in environmental $\mathrm{P} i$ concentrations [35]. Expression of phoB (Xoo3666) and phoR (Xoo3667) was also upregulated by 17 - and 12 -fold at $5 \mathrm{~min}$, respectively (Additional file 9: Figure S4A). oprO (Xoo2460 encoding the polyphosphate-selective porin $\mathrm{O}$ ) is found in the same operon and its expression was upregulated until 15 min (Fig. 3c). Among ppk and $p p x$ genes involved in polyphosphate metabolism, ppk (Xoo3668) was upregulated within $30 \mathrm{~min}$ by 2 -fold (Additional file 9: Figure S4B).

Another two-component system of PhoP-PhoQ system regulates the expression of hundreds of genes encoding virulence proteins with various properties, including intracellular survival, invasion and lipid A structure via response to the magnesium ion [36]. phoP (Xoo0423) and phoQ (Xoo0424) were upregulated by 3 -fold at $5 \mathrm{~min}$ (Additional file 9: Figure S4C).

\section{Chemotaxis and motility-related genes}

Chemotaxis and motility-related genes comprise of those encoding chemoreceptors, chemotaxis proteins, twitching motility proteins, flagella motor proteins, pilus biogenesis proteins and pilus assembly proteins [14]. Motility-related genes like fliEFGHIJKLMNOPQR and flgBCDEFGHIJKL were downregulated up to $10 \mathrm{~min}$, and were then upregulated between 10 and $60 \mathrm{~min}$ (Fig. 4a). At $5 \mathrm{~min}$, the expressions of fliM (Xoo2608 encoding the flagella motor switch protein), fliN (Xoo2609 encoding the flagella motor switch protein), fleN (Xoo2620 encoding the flagella biosynthesis switch protein) motC (Xoo2830 flagella motor protein), and motB (Xoo2831 encoding the flagella motor protein MotD) were downregulated by $0.7,0.7,0.4,0.4$ or 0.5 -fold, respectively and they were upregulated at $30 \mathrm{~min}$ by $2.7,2.3,2.0,2.9$ or 3.0-fold, respectively (Fig. 4c). Their continued expression at substantially high levels was observed for up to $60 \mathrm{~min}$. Chemotaxis related genes like che $W$, che $Y$ and cheR exhibited patterns similar to the flagella genes (Fig. 4b).

Expression of $h r p G$ was previously reported to repress chemotaxis and flagella biosynthesis-related genes and consequently repress bacterial motility [37], which is consistent with our data. HrpG was expressed at $5 \mathrm{~min}$ and began to decrease immediately after $10 \mathrm{~min}$. Prior to the 10 min time point, chemotaxis and motility related genes were downregulated, but their expression subsequently increased until $30 \mathrm{~min}$ followed by a slow decrease. When we compared the expression of chemotaxis and motility-related genes with that from other in vitro system using a minimum medium [30], the chemotaxis genes in the minimum medium system showed the downregulated expression pattern similar to that at 5 to 10 min of our in vitro system using RLX (Additional file 10: Table S6). The motility-related genes in the minimum medium system showed mostly upregulated expressions.

\section{Cyclic-di-GMP control-related genes}

Cyclic-di-GMP, a universal bacterial second messenger, regulates cell cycle progression, development, cell motility, virulence, biofilm formation, RNA modulation, bacterial predation and responses to a variety of environmental stimuli including stress [15-20, 38]. The level of cyclic-di-GMP is modulated by cyclic-di-GMP synthetases and hydrolases containing GGDEF, EAL and HD-GYP domains [38]. Change in cyclic-di-GMP level affects the functional activity of the global regulator Clp [39]. Most Clp-dependent genes are associated with virulence functions and deletion of clp abolishes virulence of the phytopathogen [39].

In Xoo, 11 GGDEF domain-containing proteins exist, among which gene products of Xoo2614, Xoo2615 and Xoo2787 were downregulated before $10 \mathrm{~min}$ and upregulated from 15 to $60 \mathrm{~min}$ (Fig. 4d). Xoo2561 and Xoo2616 from amongst the five EAL-GGDEF domain-containing proteins and Xoo4220 from amongst the three HD-GYP domain-containing proteins were similarly downregulated until $15 \mathrm{~min}$ and subsequently upregulated (Additional file 11: Figure S5). The absolute expression level of Clp was very high (RPKM: 1200-1400), but the fold changes in expression were very low (between 0.88 and 1.28). We speculate that Clp activity may be controlled after transcription, possibly posttranslationally via binding with its ligand, cyclic-di-GMP.

\section{Sugar transport-related genes}

The fructose-specific phosphotransferase system (PTS) exists ubiquitously in gram-negative bacteria [40]. The fructose-specific PTS, including the carbohydrate selective porin encoded by $r p f N$, is important for the growth and pathogenicity of many phytobacteria [41]. The absence of the sugar porin reduces carbohydrate uptake and induces synthesis of cell wall-degrading enzymes to increase sugar supply [42, 43].

Xoo has a fructose-specific PTS, consisting of fruB (Xoo2810 encoding the multi-phosphoryl transfer protein), fruK (Xoo2811 encoding the 1-phosphofructokinase), and fruA (Xoo2812 encoding the PTS fructose-specific transporter subunit IIBC); all of which were upregulated at 


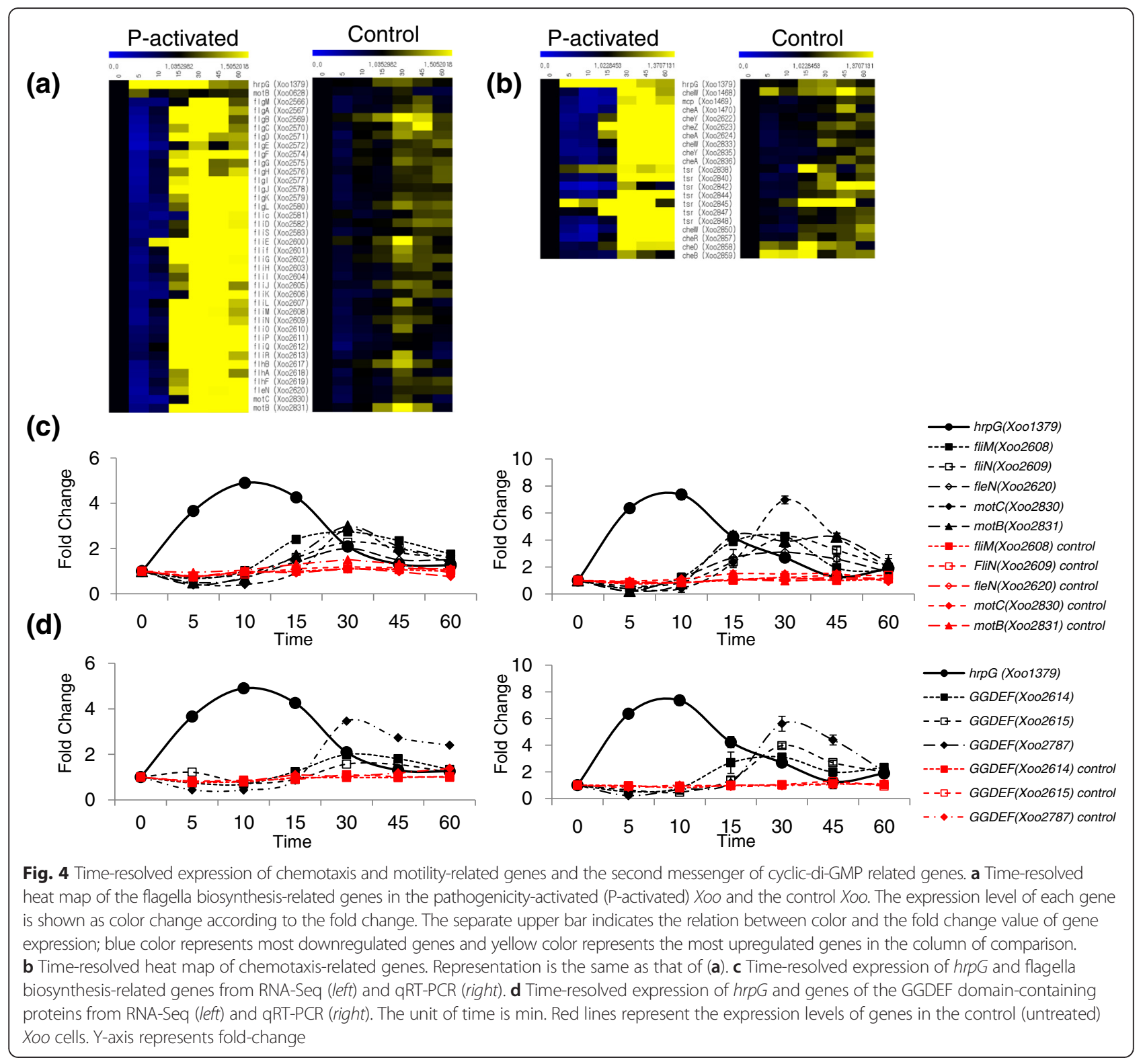

5 min (Fig. 5a). In the same operon, $r p f N$ (Xoo2813), a regulator of pathogenicity factors (carbohydrate selective porin), was also upregulated at $5 \mathrm{~min}$. Carbohydrates obtained through $\mathrm{RpfN}$ and fructose-specific PTS could be used for extracellular polysaccharide (EPS) biosynthesis [41]. In our study, the genes gumN, gumG, gumF, gumE, gumD, gumC and gumB were upregulated from $5 \mathrm{~min}$ and the genes gumM, gumL, gumK, gumJ, gumI and gumH were upregulated from 10 to $15 \mathrm{~min}$ (Fig. $5 \mathrm{~b}$ and Additional file 12: Figure S6). When we compared the expression of EPS biosynthetic gum genes with that from the minimum medium system [30], the similar upregulated expression pattern was observed in both systems (Additional file 13: Table S7).

\section{T2SS substrate genes}

Substrates of the Type II secretion system (T2SS) such as proteases, lipases and cell wall-degrading enzymes, facilitate bacterial infection by degrading plant cell walls. Recent studies showed that the substrate genes of T2SS belong to the HrpG or HrpX regulon [44]. Our results showed that $h \operatorname{trA}$, which encodes the protease DO, was upregulated from 5 to $10 \mathrm{~min}$ (Additional file 14: Figure S7A). egl (Xoo0281 encoding the cellulase), celS (Xoo1076 encoding the cellulase S), and $x y n B$ (Xoo1371 encoding the xylanase) were also upregulated in a similar manner. In contrast, other genes like egl (XooO282 encoding the cellulase), Xoo1077 (encoding the cellulase S), engXCA (Xoo4019 encoding the cellulase), and Xoo4035 (encoding 

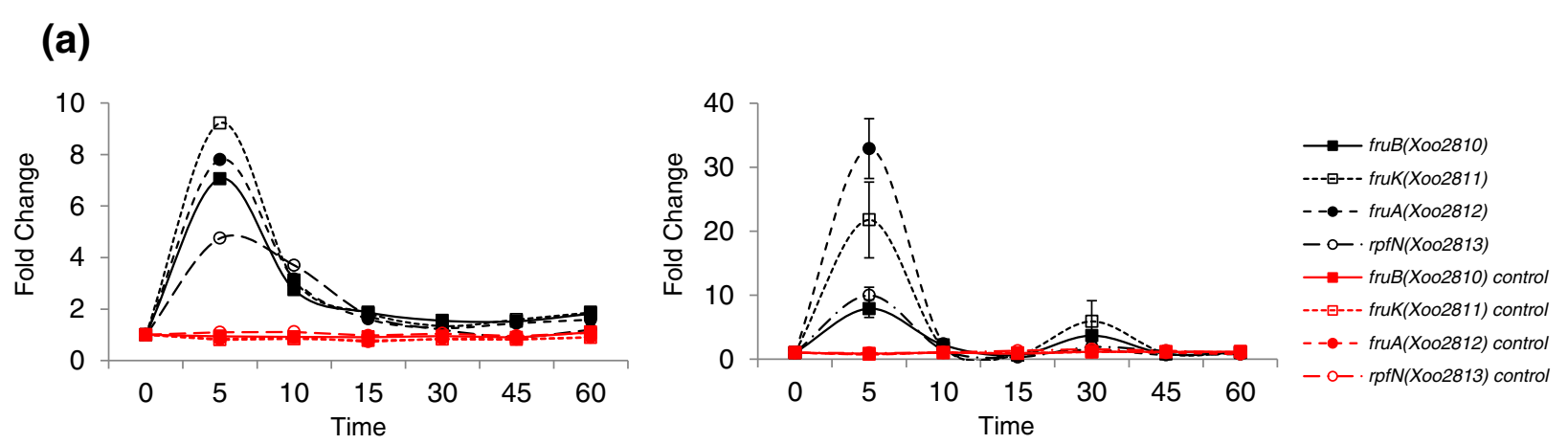

(b)
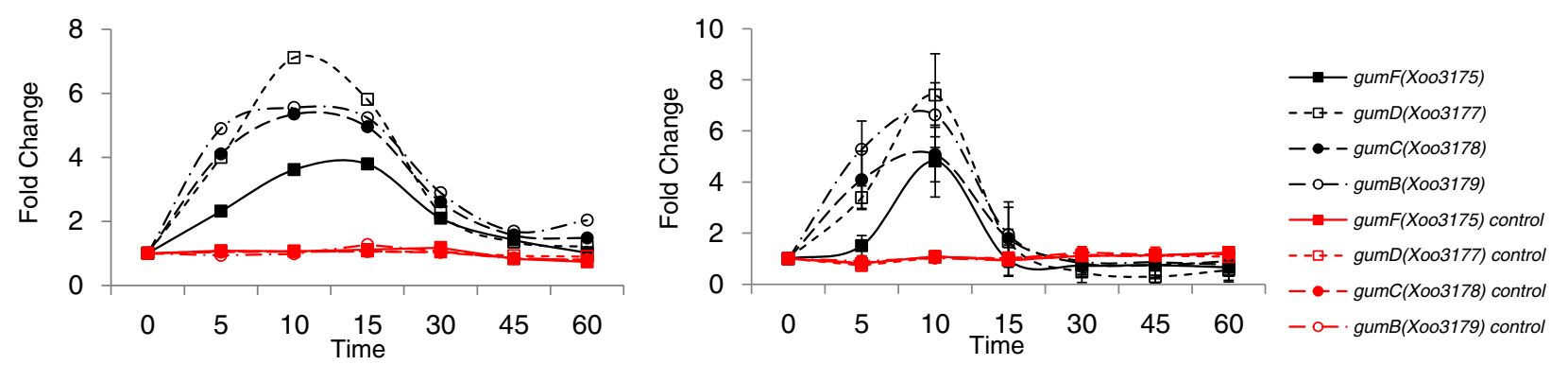

Fig. 5 Time-resolved expression of sugar transport-related genes. a Time-resolved expression of fructose-specific phosphotransferase system genes and the carbohydrate selective porin gene, rpfN, from RNA-Seq (left) and qRT-PCR (right). b Time-resolved expression of gum operon genes from RNA-Seq (left) and qRT-PCR (right). The unit of time is min. Red lines indicate the expression levels of genes in the control (untreated) Xoo cells. Y-axis represents fold-change

the 1, 4-beta-cellobiosidase) were downregulated in our system (Additional file 14: Figure S7B). In Xoo, there are three egl genes: Xoo0281, Xoo0282 and Xoo0283 that encode cellulases. Their expression patterns were all different: the expression of Xoo0281 was upregulated from 5 to $60 \mathrm{~min}$, the expression of $\mathrm{XooO283}$ was initially downregulated from 5 to $10 \mathrm{~min}$ and then upregulated from 30 to $60 \mathrm{~min}$, and the expression of Xoo0282 was downregulated from $15 \mathrm{~min}$. The different expression patterns of each copy might arise from the neofunctionalization of functional divergence from gene duplication.

\section{Essentiality of transcriptionally upregulated pathogenicity-related genes}

We studied whether the transcriptionally upregulated genes are essential for causing bacterial blight (Additional file 15: Table S8). Pathogenicity tests were performed by measuring lesion length in the leaf of Xoo-susceptible rice Milyang23 [45] after infection with 6 Xoo strains including wild-type and single-gene knockout mutants of oprO(Xoo1104), hrpX' (Xoo1380), fruA- (Xoo2812), fliC ${ }^{-}$(Xoo 2581) and gum $C^{-}$(Xoo3178). hrpX (Xoo1380) was essential for Xoo pathogenicity (Fig. 6). In different Xoo strains of KACC10859, the mutants of hrp genes like $h r p B, h r p E$, $h r p D 6, h r p D 5$, as well as $h r p G$ also showed no pathogenicity [46]. In the sugar transport signaling pathway, gumC (Xoo3178) which was upregulated at $5 \mathrm{~min}$, was also strictly required for pathogenicity. In the KACC10859 strain, various gum genes were tested to assess their relation to pathogenicity with a different $\mathrm{Xoo}$-susceptible rice cultivar, IR24 [47]. In addition to gumC, other genes like gumB, gumD, gumE, gumH and gumK were also essential for pathogenicity. The pathways involved in hrp and gum expression could be good target pathways to nullify the pathogenicity of Xoo. In our pathogenicity tests, not all the upregulated genes were essential to cause bacterial blight. For instance, upregulated genes such as oprO (Xoo1104), fliC (Xoo2581) and fruA (Xoo2812) were not essential for pathogenicity.

\section{Discussion}

Although plant responses upon initial interaction with pathogens have been actively studied for the purpose of finding new disease-resistant genes or elucidating disease-development mechanisms, little is known about how the pathogens respond to initial interactions. In vivo and in vitro systems are available for studying the plant-pathogen interactions between rice and Xoo. The in vivo system involves local Xoo inoculation into rice leaf, which is useful to study the hypersensitive response of rice: for example, the resistance response of specific rice cultivars against specific Xoo strains. However, it is difficult to study the pathogenic responses of Xoo at the site of inoculation by using the in vivo system. 


\section{(a) \\ Lesion Length}
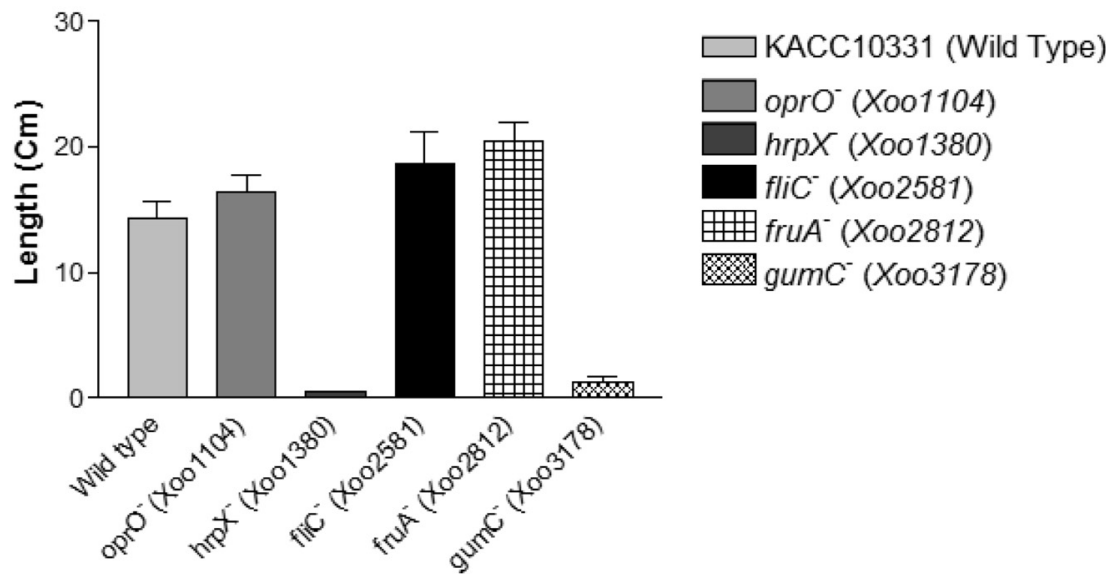

(b)
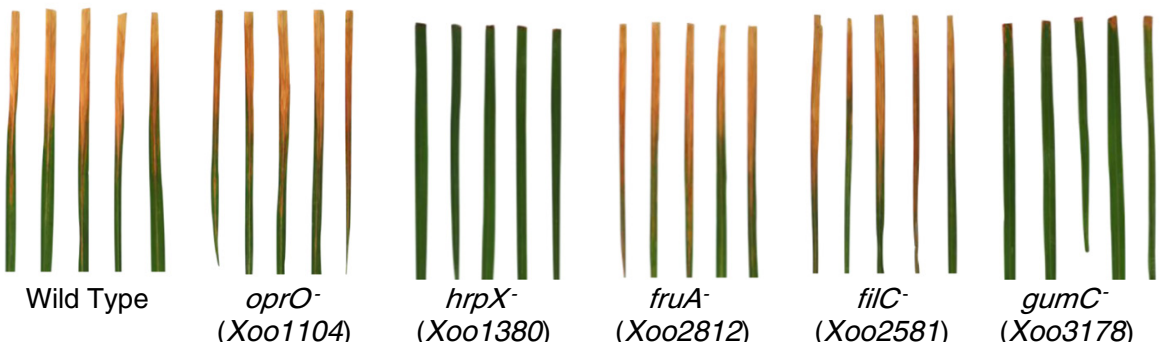

Fig. 6 Pathogenicity test of transcriptionally upregulated genes using the lesion length test. a Lesion length in Xoo-susceptible rice leaves infected by single-gene knockout Xoo mutants. b Infected rice leaves in multiple experiments

The in vitro system can allow control of the initial interactions between plant and pathogen in a timedependent manner, even though interaction in the in vitro system could be different from the real in vivo interactions. The conventional in vitro system for the activation of pathogenicity of phytopathogen uses minimum media or nutrient-poor synthetic media such as XOM2, XOM3 and XVM2 [24-26]. XOM2 is a minimum media that uses xylose as the only sugar source and has no plant-derived factors, only constitutive activation of pathogenicity is obtained. The pathogenicity activation of Xanthomonas at a specific time requires the switching of culture media to minimum media, which is not technically possible without affecting many other environmental factors. A single-gene knockout strain of the pathogen has been compared with the wildtype strain to study the pathogenicity under the condition of consistent pathogenicity-activation. For example, microarray data from Xanthomonas axonopodis pv. citri were analyzed between a wild-type strain and mutant strains of hrpG or hrpX on XVM2 medium [26].

In the present study, we used a different in vitro system to activate the pathogenicity of Xoo via RLX treatment, which is closer to an in vivo system compared to the conventional in vitro system that uses minimum media. Our in vitro assay system mimics the initial interactions between rice and Xoo by treating the Xoo cell culture with RLX from a Xoo-susceptible rice cultivar (Milyang23) at its exponential growth stage. The RLX was freshly prepared to contain all the factors from rice leaves. Initial infections by Xoo usually occur through scars on rice leaves. The damaged regions of leaves allow Xoo cells to penetrate rice tissues easily and can provide signals for Xoo cells to activate their pathogenicity. The in vitro assay system using RLX treatment is designed to mimic these initial in vivo interactions. RLX is the total extract of rice leaves prepared by grinding fresh leaves in liquid nitrogen. Even though RLX treatment cannot exactly replicate the initial interaction signals, we speculate that RLX contains all the components that can be extracted from damaged leaves. Considering the pathogen, the state of Xoo cells at the time of RLX treatment may be different from the in vivo condition at the infection site in terms of nutrition, inorganic ions, pathogen population and environmental stress. However, in our in vitro assay system, all Xoo cells in culture receive the pathogenicity- 
activation signal from RLX simultaneously, which enables us to study the initial pathogenicity signals in a synchronized manner from a homogeneous population of Xoo cells providing an amplified signal-to-noise ratio. At in vivo infection site, the pathogenicity-related interactions could be heterogeneous from cell to cell and it is difficult to control and study these interactions at a single-cell level.

The in vitro assay system using RLX treatment was combined with RNA-Seq to study the time-dependent changes of genome-wide gene expression in pathogenicity-activated Xoo cells. The transcriptional expression response of Xoo at 5 min upon RLX treatment indicates how rapidly Xoo can respond to signals from the host rice. Our in vitro system showed the transient transcriptional up- or downregulation of pathogenicity-related genes upon the interaction with RLX. Thus far, the plant-pathogen interactions have been studied mostly in a time point and generally considered as persistently sustained throughout the interactions. In cases of animal pathogens like Salmonella, Streptococcus pneumonaie, Streptomyces coelicolor and Escherichia coli, the transient transcriptional upregulation (so-called transcription surge) which is similar to our result has been known [48-51]. The animal pathogens also have the conserved pathogenic systems of T3SS, effectors and TCS like plant pathogens. Currently, we do not understand if the virulence mechanism of Xoo or plant pathogen is conserved with that of the animal pathogens. However, we should be aware that the gene expression of pathogen upon plant-pathogen interactions can change dramatically depending on time, especially at the early stage.

The transient expression and different expression time of pathogenic genes also implies that there could be multiple stages in the Xoo-mediated infection and disease development. For instance, the initial stage may be the recognition of damage on rice leaf tissues by Xoo via direct contact, the middle stage could be the penetration of damaged rice leaf tissues and effector secretion by Xoo, and the later stages could involve the proliferation of Xoo cells from the infection site by evading the resistance response by rice.

Among 20 categories of COG, iron-uptake and inorganic phosphate-uptake genes in category $\mathrm{P}$ were the most noticeable early upregulated genes, which implies that one of the putative factors from rice to activate the pathogenicity of Xoo could be inorganic ions. The inorganic ions are actively depleted by rice and unavailable for $X o o$, but the damaged rice tissues will release the essential inorganic nutrients for Xoo. We treated RLX on the exponentially growing state of Xoo, when most nutrients could start running out. In that case, when Xoo cells are in need of nutrients, Xoo cells seem to be supplied the necessary factors from the damaged rice tissues including inorganic ions. We should further investigate the needs of Xoo for nutrimental components and the environmental condition at the RLX treatment.
Many pathogenicity-related genes were expressed as early as $5 \mathrm{~min}$ in our system and it is difficult to further divide the $5 \mathrm{~min}$ time interval by every minute in order to study the gene expression pattern at finer time points. Herein, we introduced the non-linear regression method by using multiple time-point RNA-Seq data. An ordinary heat map of RNA-Seq represented the extent of up- or downregulated expression of a specific gene compared to a single reference point. Our time-dependent expression data of a gene are not a single point but rather multiple points that could be connected with the neighboring time points of every $5 \mathrm{~min}$, which helped us to extend discontinued gene expression data to continuous data (Figs. 2, 3, 4, 5 and Additional file 6: Figure S2, Additional file 8: Figure S3, Additional file 9: Figure S4, Additional file 11: Figure S5, Additional file 12: Figure S6, Additional file 14: Figure S7, Additional file 16: Figure S8) and generate a time-resolved continuous gene expression heat map for the better interpretation of the initial rice-Xoo interaction (Fig. 7a). Although the representations using the non-linear regression method could be just a visual aid, it is better than the simple comparison of expression levels or slopes of increasing or decreasing gene expression levels between two consecutive time points. For example, the maximal expressions of HrpG and HrpX were observed at 10 and $15 \mathrm{~min}$, respectively. In the time-resolved continuous presentation, the expected HrpG expression is higher than that of HrpX between 0 and 5 min (Fig. 3a). In the timeresolved continuous heat map, the hierarchy of transcriptional signals could be speculated better. The flagella-related genes were downregulated mostly at $5 \mathrm{~min}$, and chemotaxis related genes were downregulated mostly at $10 \mathrm{~min}$, which was not evident in the normal discontinuous heat map.

\section{Conclusions}

In this study, we combined the in vitro assay system with RNA-Seq to study the time-resolved genome-wide gene expression of Xoo cells upon initial interactions with RLX. Pathogenicity of Xoo was activated immediately within minutes of the interaction with RLX (Fig. 7b), involving differentially expressed genes belonging either to the same or different pathways. The time information was previously unavailable with the conventional in vivo and in vitro assay system. Our in vitro system also enables the use of the wild-type strain of Xoo as the genetic background. We can initiate the pathogenicity of Xoo at any time with the present in vitro assay system. The timely order of pathogenic gene expression is useful to understand the plant-pathogen interactions at the infection site. Our gene expression data with the 5 min resolution provide an additional dimension of time to study the conventional RNA-Seq data of the expression 


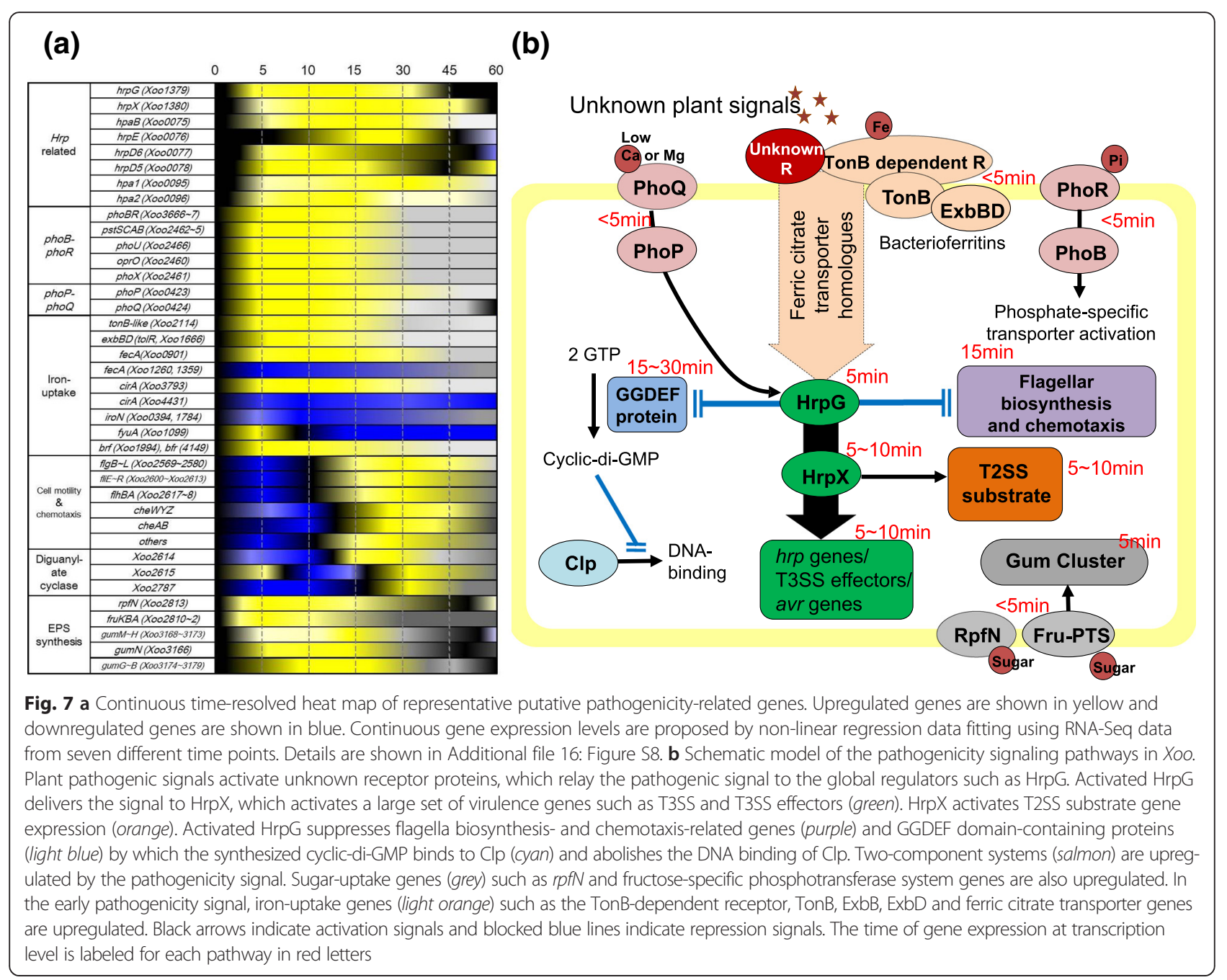

of each gene in the genome. Our in vitro system combined with RNA-Seq will be useful to study the gene expression order or hierarchy between pathogenicity-related genes and the detail time-resolved gene expression such as transient up- or downregulation of pathogenic gene expression upon plant-pathogen interactions.

\section{Methods}

\section{Bacterial strain and culture conditions}

Xanthomonas oryzae pv. oryzae (Xoo) KACC10331 was obtained from the Korean Agricultural Collection Center (KACC), which has 4,941,439 nucleotides and 4065 protein genes and no autonomous plasmids were apparent [5]. Хoo KACC10859 is not yet completely sequenced. The bacteria were grown in nutrient broth (Difco, Detroit, MI, USA) or YGC (2.0 \% D-(+)-glucose, $2.0 \%$ $\mathrm{CaCO}_{3}, 1.0 \%$ yeast extract, $1.5 \%$ agar) in a shaking incubator at $28{ }^{\circ} \mathrm{C}$ with an agitation speed of $200 \mathrm{rpm}$. The single-gene knockout mutants of Xoo were generated by the insertion of transposons containing a kanamycin resistant gene as the selection marker. To select the knockout mutants when necessary the culture medium was supplemented with $10 \mu \mathrm{L} \cdot \mathrm{mL}^{-1}$ kanamycin.

\section{Treatment of rice leaf extract and total RNA extraction from Xoo cells}

Rice was grown on a paddy field at Suwon in South Korea $\left(37^{\circ} 15^{\prime} 43.8^{\prime \prime} \mathrm{N} 126^{\circ} 59^{\prime} 15.8^{\prime \prime} \mathrm{E}\right)$ before panicle initiation (approximately 8-9 weeks). The rice leaves (Oryza sativa L. $c v$. Milyang 23; a Xoo-susceptible rice cultivar) (40 clumps) were harvested and homogenized in liquid nitrogen with a mortar and pestle. The resulting homogenate (RLX) was aliquoted to $1 \mathrm{~g}$ in Eppendorf-tubes and stored at $-80{ }^{\circ} \mathrm{C}$. A $40 \mathrm{~mL}$ culture of Xoo was grown in nutrient broth to the mid-exponential phase $\left(\mathrm{A}_{600}\right.$ of 0.5$)$ in a shaking incubator at $28{ }^{\circ} \mathrm{C}$ with an agitation speed of $200 \mathrm{rpm}$ and an RLX aliquot $(1 \mathrm{~g})$ was added to the culture medium. Samples $(1.5 \mathrm{~mL})$ of the culture were harvested from the shaking $40 \mathrm{~mL}$ culture at specified time intervals, centrifuged at $10,000 \times g$ for $5 \mathrm{~min}$ at room 
temperature, and immediately mixed with RNA protect Bacterial Reagent (Qiagen, Valencia, CA, USA). Total RNA was extracted from each sample of the harvested Xoo cells separately using an RNeasy Plus Mini Kit (Qiagen) according to the manufacturer's instructions. The concentration and quality of RNA in the samples was assessed using the NanoDrop ${ }^{\mathrm{TM}} 1000$ spectrophotometer (NanoDrop Technologies, Wilmington, DE, USA). The quantity of total RNA was determined by measuring the absorbance at $260 \mathrm{~nm}$ and $280 \mathrm{~nm}$. In addition, the $\mathrm{A}_{260} /$ $\mathrm{A}_{280}$ ratio was used to assess the level of protein contamination in RNA.

\section{RNA sequencing and data analysis}

Total RNA from approximately $10 \mu \mathrm{g}$ of each sample was used as the starting material for generating sequencing libraries. Ribosomal RNA was depleted by using MICROBExpress Bacterial mRNA Enrichment Kit (Ambion, Austin, TX, USA). Enriched mRNA was prepared with the Illumina TruSeq RNA Sample Preparation Kit (Illumina, San Diego, CA, USA) following the manufacturer's instructions. As per the protocol, RNA was fragmented using the included buffer for 5 min and cleaned up. The resulting RNA was subsequently used for reverse transcription and secondstrand cDNA synthesis with random hexamer primers. Purified cDNA fragments were end-repaired, A-tailed, ligated to TruSeq sequencing adapters, and amplified by 15 cycles of PCR. One lane per sample was used for sequencing with an Illumina Genome Analyzer IIx to generate non-directional, pair-ended 36-bp reads. Quality-filtered reads were mapped to the reference genome sequence (http://www.ncbi.nlm.nih.gov/nuccore/585 79623?report=fasta) using CLC Genomics Workbench 4.0 (CLC bio, Aarhus, Denmark). Relative transcript abundance was calculated by counting the number of reads per kilobase per million mapped sequence reads (RPKM) [52].

\section{Quantitative real-time PCR (qRT-PCR)}

RNA was reverse transcribed using a PrimeScript ${ }^{\mathrm{TM}} 1$ st strand cDNA Synthesis Kit (Takara, Tokyo, Japan) with random hexamer primers. Gene-specific primers were designed to amplify sequences 100-150 bp in length from the Xoo genome using Beacon Designer ${ }^{\mathrm{TM}} 8.0$ (Premier Biosoft, Palo Alto, CA, USA). Real-time PCR was performed with a CFX96 ${ }^{\mathrm{TM}}$ Real-Time System (BioRAD, Hercules, CA) using the $\mathrm{iQ}^{\mathrm{TM}}$ SYBR Green Supermix (Bio-RAD) following the manufacturer's instructions. The $16 \mathrm{~S}$ rRNA gene was used as an endogenous control. The expression level of each gene was calculated using three biological replicates. Fold changes of relative and normalized expression values were calculated with data from CFX Manager 3.0 (Bio-Rad).

\section{Time-resolved continuous heat map analysis}

$\log _{2}$-scaled RPKM values from RNA-Seq data at each time point within the first hour post-RLX treatment were fitted to a curve and non-linear regression was performed using GraphPad Prism (version 3.02 for Windows, GraphPad Software, San Diego California USA, www.graphpad.com) to obtain the resulting continuous RPKM values vs. time from the fitted curve. The maximum expressed level of each gene within $1 \mathrm{~h}$ was set as 1.0 and the continuous expression level vs. time was scaled based on the maximum reference level. When the expressed level was downregulated compared with that at $0 \mathrm{~h}$, the lowest expressed level was set to -1.0 and the continuous expression level was scaled in the same manner. The increasing and decreasing expression level of each gene was compared with other genes in time-resolved continuous heat map. Heat maps were generated with $\mathrm{MeV}$ (Multi Experiment Viewer) [53] by adding the fold changes of RPKM values into a single-color array.

\section{Insertional transposon mutagenesis of Xanthomonas oryzae pv. oryzae}

To perform transposon mutagenesis, $1 \mu \mathrm{L}$ of Transposome $^{\mathrm{TM}}$ (20 ng. $\mu \mathrm{L}^{-1}$; Epicentre Technologies, Madison, WI, USA) was mixed with $50 \mu \mathrm{L}$ of Xoo electrocompetent cells and placed in a $0.2 \mathrm{~cm}$ gap electroporation cuvette (Bio-Rad). A single high-voltage pulse $(12.5 \mathrm{kV} / \mathrm{cm}$ for $5 \mathrm{~ms}$, with a resistance value of $200 \Omega$ and capacitance of $25 \mu \mathrm{F}$ ) was applied with the Gene Pulser II system (BioRad). After pulse delivery, the cells were immediately removed from the electroporation cuvette and inoculated into $1 \mathrm{~mL}$ of SOC medium (2.0\% tryptone, $0.5 \%$ yeast extract, $0.05 \% \mathrm{NaCl}, 20 \mathrm{mM}$ glucose) without antibiotics. The cells were incubated for $18 \mathrm{~h}$ at $28{ }^{\circ} \mathrm{C}$ with constant shaking $(120 \mathrm{rpm})$. After incubation, the putative transformants were plated onto nutrient agar plates containing $10 \mu \mathrm{L} \cdot \mathrm{mL}^{-1}$ of kanamycin and incubated at $28{ }^{\circ} \mathrm{C}$ for 3 days. To select the transposon-inserted mutants from colonies, genomic DNA was isolated using the genomic DNA extraction kit (DNeasy Mini Kit, Qiagen). The genomic flanking sequences of the transposon were amplified by thermal asymmetric interlaced (TAIL)-PCR with KOD-Plus DNA polymerase (Toyobo, Japan) using the primer KAN2F (5'-CTCGATGAGTTTTTCTAATCAGAAT-3'). The first 30 cycles of the PCR were carried out at $55^{\circ} \mathrm{C}$, with a $30 \mathrm{~s}$ extension. The next 30 cycles were carried out at $30{ }^{\circ} \mathrm{C}$, with a similar extension time, and the last 30 cycles were performed at $55^{\circ} \mathrm{C}$ with a 2 min extension. One microliter of the TAIL-PCR product and primer KAN-2 FP-1 (5'ACCTACAACAAAGCTCTCATCAACC-3') were used in ' $2 \times$ ' Big Dye Terminator sequencing reactions, according to the manufacturer's protocols (PE Applied Biosystems). To confirm whether the mutants obtained were derived from true transposition or not, southern 
hybridization was carried out with genomic DNA from the mutants, digested with EcoRI and separated by electrophoresis in $0.8 \%$ agarose gel. The transposon was labeled as the probe with $[\alpha-32 \mathrm{P}] \mathrm{dCTP}$ using the random priming method according to the manufacturer's instructions (LaddermanTM Labeling kit, Takara, Japan).

\section{Pathogenicity assay}

Leaves of 4-to-6-week-old Xoo-susceptible rice plant (Oryza sativa L. $c v$. Milyang 23)-five of the uppermost leaves of each plant-were used for pathogen inoculation by the leaf cutting method [45], which consists of clipping the leaf tip with sterile scissors dipped in a suspension of a mutated Xoo strain in sterile water at a concentration of $\mathrm{A}_{600}=0.5$. The plants were inoculated in a greenhouse maintained between 25 and $30{ }^{\circ} \mathrm{C}$, and a relative humidity of $60 \%$. The control plants were inoculated similarly with sterile water under the same conditions. Before inoculation, the leaves were thoroughly washed under running tap water to remove dirt, surface disinfected in $70 \%$ ethanol, and rinsed thrice with sterile distilled water. The susceptible rice was inoculated with the Xoo strain (five replicates each), and lesion lengths were measured after two weeks.

\section{Accession number}

The RNA-Seq data were deposited in NCBI GEO (Gene Expression Omnibus) with the accession number GSE61607.

\section{Availability of data and materials}

The RNA-Seq data were deposited in NCBI GEO (Gene Expression Omnibus) with the accession number GSE61607.

\section{Additional files}

Additional file 1: Table S1. RPKM values of RNA-Seqs of the pathogenicity-activated and control Xoo cells. (XLSX 1168 kb) Additional file 2: Table S2. Randomly selected 28 genes for qRT-PCR and their p-values with RNA-Seq data. (DOCX $26 \mathrm{~kb}$ )

Additional file 3: Table S3. Sequence reads for pathogenicity-activated and control Xoo cells. (DOCX $16 \mathrm{~kb}$ )

Additional file 4: Figure S1. The number of upregulated (UR) and downregulated (DR) genes for each time (min) point $0,5,10,15,30,45$ and $60 \mathrm{~min}$ in P-activated $X_{00}$ cells (upper). The number of upregulated (UR) and downregulated (DR) genes for each time (min) point 0, 5, 10, 15, 30, 45 and 60 min in control Xoo cells (lower). (PPTX 51 kb)

Additional file 5: Table S4. Differentially expressed genes in pathogenicity-activated Xoo cells (compared with the expression level at zero time with an RPKM threshold of 2.0 and a difference filter of 2.0). (DOCX $270 \mathrm{~kb}$ )

Additional file 6: Figure S2. Time-resolved expression of hrp genes including hpaB, hrpE, hrpD6, hrpD5, hpa1 and hpa2. The unit of time is $\mathrm{min}$. Red lines indicate the expression levels of genes in contro (untreated) Xoo cells. Y-axis represents fold-change. (PPTX 51 kb)
Additional file 7: Table S5. Fold changes of transcriptional expression levels of hrp genes in Xoo and Xcc from two different in vitro assay systems. (DOCX 19 kb)

Additional file 8: Figure S3. Time-resolved expression of genes related to iron-uptake. (A) Among tonB genes, Xoo2114 was upregulated 6-fold. (B) Upregulated TonB-dependent receptor genes; fecA (Xoo0901) and cirA (Xo03793) were upregulated 80- and 20-fold, respectively. (C) Downregulated TonBdependent receptor genes; iroN (Xo00394), fyuA (Xo0 1099), iroN (Xo0 1784) and cirA (Xoo4431) were downregulated 50-, 5-, 5- and 4-fold, respectively. (D) tolR (Xoo1666, exbD-like) was upregulated 2.5-fold. The unit of time is min. Red lines indicate the expression levels of genes in control (untreated) Xoo cells. Y-axis represents fold-change. (PPTX $84 \mathrm{~kb}$ )

Additional file 9: Figure S4. Time-resolved expression of two component system (TCS) genes. (A) phoB-phoR genes were upregulated within $5 \mathrm{~min}$. (B) ppk was upregulated within 5 min whereas ppx expression was not changed. (C) phoP-phoQ genes were also upregulated within $5 \mathrm{~min}$. The unit of time is min. Red lines indicate the expression levels of genes in control (untreated) Xoo cells. Y-axis represents fold-change. (PPTX $71 \mathrm{~kb}$ )

Additional file 10: Table S6. Fold changes of transcriptional expression levels of chemotaxis and motility-related genes in Xoo and Xcc from two different in vitro assay systems. (DOCX $25 \mathrm{~kb}$ )

Additional file 11: Figure S5. Time-resolved expression of EAL-GGDEF and HD-GYP containing genes. The unit of time is min. Red lines indicate expression levels of genes in control (untreated) Xoo cells. Y-axis represents fold-change. (PPTX $70 \mathrm{~kb}$ )

Additional file 12: Figure S6. Time-resolved expression of gumH-gumM genes. The unit of time is min. Red lines indicate expression levels of genes in control (untreated) Xoo cells. Y-axis represents fold-change. (PPTX 51 kb)

Additional file 13: Table S7. Fold changes of transcriptional expression levels of gum genes in Xoo and Xcc from two different in vitro assay systems. (DOCX $17 \mathrm{~kb}$ )

Additional file 14: Figure S7. Time-resolved expression of T2SS substrate genes. (A) Genes like htrA, egl (Xoo0281), cels and xynB were upregulated. (B) Genes like egl (Xo00282), Xoo1077, engXCA and Xo04035 were downregulated. egl (Xoo0283) was downregulated within $10 \mathrm{~min}$ and upregulated subsequently. The unit of time is min. Red lines indicate the expression levels of genes in control (untreated) Xoo cells. Y-axis represents fold-change. (PPTX 59 kb)

Additional file 15: Table S8. Virulence of wild-type and mutant $X_{O O}$ strains on rice. (DOCX $16 \mathrm{~kb}$ )

Additional file 16: Figure S8. Representation of continuous time-resolved gene expression of selected genes. (A) Scaled continuous time-resolved gene expression. The absolute expression levels of each gene were $\log _{2}$-scaled and the highest level was set to 1.0. The expression levels at each time point were fitted by non-linear regression method to derive time-resolved continuous gene expression levels. (B) Unscaled continuous time-resolved gene expression. The absolute expression levels of each gene were $\log _{2}$-scaled as in (A), but the highest level was not set to 1.0. The expression levels at each time point were also fitted by non-linear regression method to derive the timeresolved continuous gene expression levels. (PPTX 3239 kb)

\section{Abbreviations}

P-activated: pathogenicity activated; RLX: rice leaf extract; RPKM: reads per kilobase per million mapped reads.

\section{Competing interests}

The authors declare that they have no competing interests.

\section{Authors' contributions}

SK designed the experiments, performed the experiments and data analysis, and wrote the manuscript. YJC and SHL performed the RNA-Seq. ESS performed the experiments. JGK and LWK designed the experiments and performed the data analysis. All authors read and approved the final manuscript.

\section{Acknowledgments}

This study was supported by a grant from the Next-Generation BioGreen 21 Program (No. PJ01103102), Rural Development Administration, Republic of 
Korea; by a grant from the National Research Foundation of Korea(NRF) (No NRF-2015R1A2A2A01004375) and by a research grant from the National Research Laboratory Program through the National Research Foundation of Korea (NRF) funded by the Ministry of Science, ICT and Future Planning (No. 2011-0027928).

\section{Author details}

'Genomics Division, National Academy of Agricultural Science (NAAS), Rural Development Administration (RDA), Jeonju 54874, Korea. ${ }^{2}$ Chunlab, Inc., Seoul National University, Seoul 08826, Korea. ${ }^{3}$ Department of Biological Sciences, National Leading Research Laboratory of Drug Resistance Proteomics, Myongji University, 116 Myongjiro, Yongin, Gyeonggido 17058, Korea. ${ }^{4}$ Department of Biological Sciences, Konkuk University, 1 Hwayang dong, Gwangjin-gu, Seoul 05029, Korea.

Received: 25 November 2015 Accepted: 25 April 2016

Published online: 10 May 2016

\section{References}

1. Jones JD, Dangl JL. The plant immune system. Nature. 2006:444(7117):323-9.

2. Li JY, Wang J, Zeigler RS. The 3,000 rice genomes project: new opportunities and challenges for future rice research. GigaScience. 2014;3:8.

3. Mew TW, Alvarez AM, Leach JE, Swings J. Focus on bacterial-blight of rice. Plant Dis. 1993;77(1):5-12.

4. Suh JP, Jeung JU, Noh TH, Cho YC, Park SH, Park HS, Shin MS, Kim CK, Jena KK. Development of breeding lines with three pyramided resistance genes that confer broad-spectrum bacterial blight resistance and their molecular analysis in rice. Rice. 2013;6(1):5.

5. Lee BM, Park YJ, Park DS, Kang HW, Kim JG, Song ES, Park IC, Yoon UH, Hahn JH, Koo BS et al. The genome sequence of Xanthomonas oryzae pathovar oryzae KACC10331, the bacterial blight pathogen of rice. Nucleic Acids Res. 2005;33(2):577-86.

6. Zhang H, Wang S. Rice versus Xanthomonas oryzae pv. oryzae: a unique pathosystem. Curr Opin Plant Biol. 2013;16(2):188-95.

7. Leyns F, De Cleene M, Swings J, de Ley J. The host range of the genus Xanthomonas. Bot Rev. 1984;50:308-55.

8. Broek AV, Vanderleyden J. The role of bacterial motility, chemotaxis, and attachment in bacteria plant interactions. Mol Plant-Microbe Interact. 1995:8(6):800-10.

9. Shen $Y$, Ronald P. Molecular determinants of disease and resistance in interactions of Xanthomonas oryzae pv. oryzae and rice. Microbes Infect/ Institut Pasteur. 2002;4(13):1361-7

10. Brencic A, Winans SC. Detection of and response to signals involved in host-microbe interactions by plant-associated bacteria. Microbiol Mol Biol R. 2005;69(1):155-+.

11. Brito B, Marenda M, Barberis P, Boucher C, Genin S. prhJ and hrpG, two new components of the plant signal-dependent regulatory cascade controlled by PrhA in Ralstonia solanacearum. Mol Microbiol. 1999;31(1):237-51.

12. Litwin CM, Calderwood SB. Role of Iron in Regulation of Virulence Genes. Clin Microbiol Rev. 1993;6(2):137-49.

13. Blanvillain S, Meyer D, Boulanger A, Lautier M, Guynet C, Denance N, Vasse J, Lauber E, Arlat M. Plant Carbohydrate Scavenging through TonBDependent Receptors: A Feature Shared by Phytopathogenic and Aquatic Bacteria. PLoS One. 2007;2(2):e225.

14. Zhang F, Du Z, Huang L, Vera Cruz C, Zhou Y, Li Z. Comparative transcriptome profiling reveals different expression patterns in Xanthomonas oryzae pv. oryzae strains with putative virulence-relevant genes. PLoS One. 2013;8(5):e64267.

15. Duerig A, Abel S, Folcher M, Nicollier M, Schwede T, Amiot N, Giese B, Jenal U. Second messenger-mediated spatiotemporal control of protein degradation regulates bacterial cell cycle progression. Gene Dev. 2009;23(1):93-104.

16. He YW, Zhang LH. Quorum sensing and virulence regulation in Xanthomonas campestris. Fems Microbiol Rev. 2008;32(5):842-57.

17. Hobley L, Fung RKY, Lambert C, Harris MATS, Dabhi JM, King SS, Basford SM, Uchida K, Till R, Ahmad R et al. Discrete Cyclic di-GMP-Dependent Contro of Bacterial Predation versus Axenic Growth in Bdellovibrio bacteriovorus. Plos Pathog. 2012;8(2):e1002493.

18. Kuchma SL, Connolly JP, O'Toole GA. A three-component regulatory system regulates biofilm maturation and type III secretion in Pseudomonas aeruginosa. J Bacteriol. 2005;187(4):1441-54.
19. Tamayo R, Pratt JT, Camilli A. Roles of cyclic diguanylate in the regulation of bacterial pathogenesis. Annu Rev Microbiol. 2007:61:131-48.

20. Weber H, Pesavento C, Possling A, Tischendorf G, Hengge R. Cyclic-di-GMPmediated signalling within the sigma(S) network of Escherichia coli. Mol Microbiol. 2006;62(4):1014-34.

21. Gotoh Y, Equchi Y, Watanabe T, Okamoto S, Doi A, Utsumi R. Twocomponent signal transduction as potential drug targets in pathogenic bacteria. Curr Opin Microbiol. 2010;13(2):232-9.

22. Arlat M, Gough CL, Zischek C, Barberis PA, Trigalet A, Boucher CA. Transcriptional Organization and Expression of the Large Hrp Gene-Cluster of PseudomonasSolanacearum. Mol Plant-Microbe Interact. 1992;5(2):187-93.

23. Rahme LG, Mindrinos MN, Panopoulos NJ. Plant and Environmental Sensory Signals Control the Expression of Hrp Genes in Pseudomonas-Syringae-Pv Phaseolicola. J Bacteriol. 1992;174(11):3499-507.

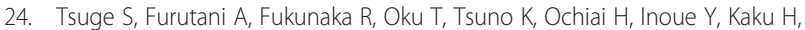
Kubo Y. Expression of Xanthomonas oryzae pv. oryzae hrp Genes in XOM2, a Novel Synthetic Medium. J Gen Plant Pathol. 2002:68:363-71.

25. Seo YS, Sriariyanun M, Wang L, Pfeiff J, Phetsom J, Lin Y, Jung KH, Chou HH, Bogdanove A, Ronald P. A two-genome microarray for the rice pathogens Xanthomonas oryzae pv. oryzae and X. oryzae pv. oryzicola and its use in the discovery of a difference in their regulation of hrp genes. Bmc Microbiol. 2008;8:99.

26. Guo Y, Figueiredo F, Jones J, Wang N. HrpG and HrpX play global roles in coordinating different virulence traits of Xanthomonas axonopodis pv. citri. Mol Plant-Microbe Interact. 2011;24(6):649-61.

27. Astua-Monge G, Freitas-Astua J, Bacocina G, Roncoletta J, Carvalho SA, Machado MA. Expression profiling of virulence and pathogenicity genes of Xanthomonas axonopodis pv. citri. J Bacteriol. 2005;187(3):1201-5.

28. Kim S, Nguyen TD, Lee J, Hong MK, Pham TV, Ahn YJ, Lee BM, Han YS, Kim DE, Kim JG et al. Homologous expression and T3SS-dependent secretion of TAP-tagged Xo2276 in Xanthomonas oryzae pv. oryzae induced by rice leaf extract and its direct in vitro recognition of putative target DNA sequence. $J$ Microbiol Biotechnol. 2013;23(1):22-8

29. Kim SH, Lee SE, Hong MK, Song NH, Yoon B, Viet P, Ahn YJ, Lee BM, Jung JW, Kim KP et al. Homologous expression and quantitative analysis of T3SSdependent secretion of TAP-tagged XoAvrBs2 in Xanthomonas oryzae pv. oryzae induced by rice leaf extract. J Microbiol Biotechnol. 2011;21(7):679-85.

30. Liu W, Yu YH, Cao SY, Niu XN, Jiang W, Liu GF, Jiang BL, Tang DJ, Lu GT, He $Y Q$ et al. Transcriptome profiling of Xanthomonas campestris pv. campestris grown in minimal medium MMX and rich medium NYG. Res Microbiol. 2013;164(5):466-79.

31. Carrondo MA. Ferritins, iron uptake and storage from the bacterioferritin viewpoint. EMBO J. 2003;22(9):1959-68.

32. Karlsson M, Hannavy K, Higgins CF. Exbb Acts as a Chaperone-Like Protein to Stabilize Tonb in the Cytoplasm. Mol Microbiol. 1993;8(2):389-96.

33. Kampfenkel K, Braun V. Membrane Topology of the Escherichia-Coli Exbd Protein. J Bacteriol. 1992:174(16):5485-7.

34. Gorska A, Sloderbach A, Marszall MP. Siderophore-drug complexes: potentia medicinal applications of the 'Trojan horse' strategy. Trends Pharmacol Sci. 2014;35(9):442-9.

35. Chakraborty S, Sivaraman J, Leung KY, Mok YK. Two-component PhoB-PhoR Regulatory System and Ferric Uptake Regulator Sense Phosphate and Iron to Control Virulence Genes in Type III and VI Secretion Systems of Edwardsiella tarda. J Biol Chem. 2011;286(45):39417-30.

36. Prost LR, Miller SI. The Salmonellae PhoQ sensor: mechanisms of detection of phagosome signals. Cell Microbiol. 2008;10(3):576-82.

37. Jiang GF, Jiang BL, Yang M, Liu S, Liu J, Liang XX, Bai XF, Tang DJ, Lu GT, He $Y Q$, Yu DQ, Tang JL. Establishment of an inducing medium for type III effector secretion in Xanthomonas campestris pv. campestris. Braz Microbiol. 2014:44(3):945-52.

38. Chou SH, Galperin MY. Diversity of Cyclic Di-GMP-Binding Proteins and Mechanisms. J Bacteriol. 2016:198(1):32-46.

39. Romling U, Galperin MY, Gomelsky M. Cyclic di-GMP: the First 25 Years of a Universal Bacterial Second Messenger. Microbiol Mol Biol R. 2013:77(1):1-52.

40. Lengeler JW. Carbohydrate Transport in Bacteria under EnvironmentalConditions, a Black-Box. Anton Leeuw Int J G. 1993:63(3-4):275-88.

41. Moreira LM, Almeida NF, Potnis N, Digiampietri LA, Adi SS, Bortolossi JC, da Silva AC, da Silva AM, de Moraes FE, de Oliveira JC et al. Novel insights into the genomic basis of citrus canker based on the genome sequences of two strains of Xanthomonas fuscans subsp aurantifolii. BMC Genomics. 2010;11:238. 
42. Tang JL, Liu YN, Barber CE, Dow JM, Wootton JC, Daniels MJ. Genetic and Molecular Analysis of a Cluster of Rpf Genes Involved in Positive Regulation of Synthesis of Extracellular Enzymes and Polysaccharide in XanthomonasCampestris Pathovar Campestris. Mol Gen Genet. 1991;226(3):409-17.

43. Tang JL, Gough CL, Daniels MJ. Cloning of Genes Involved in Negative Regulation of Production of Extracellular Enzymes and Polysaccharide of Xanthomonas-Campestris Pathovar Campestris. Mol Gen Genet. 1990; 222(1):157-60.

44. Furutani A, Tsuge S, Ohnishi K, Hikichi Y, Oku T, Tsuno K, Inoue Y, Ochiai H, Kaku H, Kubo Y. Evidence for HrpXo-dependent expression of type II secretory proteins in Xanthomonas oryzae pv. oryzae. J Bacteriol. 2004 186(5):1374-80.

45. Akhtar MA, Rafi A, Hameed A. Comparison of Methods of Inoculation of Xanthomonas Oryzae Pv.Oryzae in Rice Cultivars. Pak J Bot. 2008;40(5):2171-5.

46. Cho HJ, Park YJ, Noh TH, Kim YT, Kim JG, Song ES, Lee DH, Lee BM. Molecular analysis of the hrp gene cluster in Xanthomonas oryzae pathovar oryzae KACC10859. Microb Pathog. 2007:44:473-83.

47. Kim SY, Kim JG, Lee BM, Cho JY. Mutational analysis of the gum gene cluster required for xanthan biosynthesis in Xanthomonas oryzae pv oryzae. Biotechnol Lett. 2009:31(2):265-70.

48. Yamamoto K, Ishihama A. Transcriptional response of Escherichia coli to external copper. Mol Microbiol. 2005;56(1):215-27.

49. Shin D, Lee EJ, Huang H, Groisman EA. A positive feedback loop promotes transcription surge that jump-starts Salmonella virulence circuit. Science. 2006;314(5805):1607-9.

50. Hutchings $\mathrm{MI}$, Hong $\mathrm{HJ}$, Buttner MJ. The vancomycin resistance VanRS twocomponent signal transduction system of Streptomyces coelicolor. Mol Microbiol. 2006;59(3):923-35.

51. Alloing G, Martin B, Granadel C, Claverys JP. Development of competence in Streptococcus pneumonaie: pheromone autoinduction and control of quorum sensing by the oligopeptide permease. Mol Microbiol. 1998;29(1):75-83.

52. Wang Z, Gerstein M, Snyder M. RNA-Seq: a revolutionary tool for transcriptomics. Nat Rev Genet. 2009;10(1):57-63.

53. Saeed Al, Sharov V, White J, Li J, Liang W, Bhagabati N, Braisted J, Klapa M, Currier T, Thiagarajan M et al. TM4: a free, open-source system for microarray data management and analysis. Biotechniques. 2003;34(2):374-8.

\section{Submit your next manuscript to BioMed Central and we will help you at every step:}

- We accept pre-submission inquiries

- Our selector tool helps you to find the most relevant journal

- We provide round the clock customer support

- Convenient online submission

- Thorough peer review

- Inclusion in PubMed and all major indexing services

- Maximum visibility for your research

Submit your manuscript at wuw biomedcentral.com/submit

C) Biomed Central 